\title{
Expression and DNA methylation levels of prolyl hydroxylases PHD1, PHD2, PHD3 and asparaginyl hydroxylase $\mathrm{FIH}$ in colorectal cancer
}

\author{
Agnieszka A Rawluszko ${ }^{1 *}$, Katarzyna E Bujnicka ${ }^{1}$, Karolina Horbacka², Piotr Krokowicz ${ }^{2}$ and Paweł P Jagodziński ${ }^{1}$
}

\begin{abstract}
Background: Colorectal cancer (CRC) is one of the most common and comprehensively studied malignancies. Hypoxic conditions during formation of CRC may support the development of more aggressive cancers. Hypoxia inducible factor (HIF), a major player in cancerous tissue adaptation to hypoxia, is negatively regulated by the family of prolyl hydroxylase enzymes (PHD1, PHD2, PHD3) and asparaginyl hydroxylase, called factor inhibiting HIF (FIH).

Methods: PHD1, PHD2, PHD3 and FIH gene expression was evaluated using quantitative RT-PCR and western blotting in primary colonic adenocarcinoma and adjacent histopathologically unchanged colonic mucosa from patients who underwent radical surgical resection of the colon $(n=90)$, and the same methods were used for assessment of PHD3 gene expression in HCT116 and DLD-1 CRC cell lines. DNA methylation levels of the CpG island in the promoter regulatory region of PHD1, PHD2, PHD3 and FIH were assessed using bisulfite DNA sequencing and high resolution melting analysis (HRM) for patients and HRM analysis for CRC cell lines.

Results: We found significantly lower levels of PHD1, PHD2 and PHD3 transcripts ( $p=0.00026 ; p<0.00001$; $p<0.00001)$ and proteins $(p=0.004164 ; p=0.0071 ; p<0.00001)$ in primary cancerous than in histopathologically unchanged tissues. Despite this, we did not observe statistically significant differences in FlH transcript levels between cancerous and histopathologically unchanged colorectal tissue, but we found a significantly increased level of FIH protein in CRC ( $p=0.0169)$. The reduced PHD3 expression was correlated with significantly increased DNA methylation in the CPG island of the PHD3 promoter regulatory region $(p<0.0001)$. We did not observe DNA methylation in the CpG island of the PHD1, PHD2 or FIH promoter in cancerous and histopathologically unchanged colorectal tissue. We also showed that 5-Aza-2'-deoxycytidine induced DNA demethylation leading to increased PHD3 transcript and protein level in HCT116 cells.
\end{abstract}

Conclusion: We demonstrated that reduced PHD3 expression in cancerous tissue was accompanied by methylation of the CpG rich region located within the first exon and intron of the PHD3 gene. The diminished expression of PHD1 and PHD2 and elevated level of FIH protein in cancerous tissue compared to histopathologically unchanged colonic mucosa was not associated with DNA methylation within the CpG islands of the PHD1, PHD2 and FIH genes.

\section{Background}

Colorectal cancer (CRC) belongs to one of the most extensively studied types of cancers due to its high mortality and severity. It is the third and second leading cause of death from malignant disease among adults in the US and Europe, respectively [1]. A decrease in oxygen concentration is widely seen during the formation

\footnotetext{
* Correspondence: arawluszko@ump.edu.pl

'Department of Biochemistry and Molecular Biology, Poznań University of Medical Sciences, Poznan, Poland

Full list of author information is available at the end of the article
}

of many solid tumors, including CRC. Hypoxic regions may occur due to poorly formed vasculature, shunting of blood and vascular permeability [2]. Cancer cells can adjust to this microenvironment by altering gene transcription to enhance glucose uptake and angiogenesis [2]. The various adaptive responses involve multiple mechanisms, of which the best-characterized is mediated through transcriptional gene activation by the hypoxia inducible factor (HIF) [3]. HIF is a heterodimeric transcription factor assembled from an oxygen-regulated $\alpha$ subunit (HIF- $\alpha$ ) and a constitutively expressed $\beta$ subunit (HIF- $\beta$ )

\section{Biomed Central}


$[3,4]$. Under hypoxic conditions, HIF- $\alpha$ translocates into the nucleus, where it forms a dimer with HIF- $\beta$ to form an active transcriptional complex with a number of cofactors $[3,4]$. The HIF complex binds to the promoter hypoxia response elements (HREs) to induce the expression of target genes that regulate the cellular adaptive response to low oxygen tension $[3,4]$.

HIF- $\alpha$ is constitutively expressed in the tissue; however, it has an extremely short half-life in normoxic conditions [3]. The level of HIF- $\alpha$ protein is regulated in several ways. The most well known is its degradation through post-translational hydroxylation. To date, two different oxygen-dependent hydroxylation mechanisms have been identified. The first pathway is initiated by three prolyl hydroxylase domain enzymes, PHD1, PHD2 and PHD3 [3]. The second pathway involves the factor inhibiting HIF (FIH) [5]. The PHD enzymes catalyze the hydroxylation of two conserved proline residues in the oxygen dependent degradation domain of the HIF- $\alpha$ protein. Hydroxylated proline residues are subsequently recognized by the E3 ligase complex containing von Hippel-Lindau tumour suppressor protein (pVHL), and targeted for degradation by the $26 \mathrm{~S}$ proteasome [3]. Similarly, FIH hydroxylates the asparagine residue within the $\mathrm{C}$-terminal transactivation domain of HIF- $\alpha[5,6]$. This results in the prevention of HIF- $\alpha$ interaction with its coactivators. Hence, under normoxic conditions, there is a dual mechanism of HIF inhibition by its degradation or inactivation by PHDs and FIH enzymes, respectively.

Recently, various studies have demonstrated inconsistent data of FIH and PHD1, 2 and 3 expression changes during CRC development [7-10]. The mechanism by which these hydroxylases might be regulated is still not well elucidated. Interestingly, $P H D s$ and $F I H$ genes possess a CpG island within their promoter region. Similarly to genetic mutations, hyper- or hypomethylation of gene regulatory sequences have been shown to potentially change the expression of cancer related genes in different malignancies, including CRC [11]. To date, it has been demonstrated that the promoter region of the PHD3 gene is hypermethylated in plasma cell neoplasia, prostate, melanoma and mammary gland cancer cell lines [12,13]. The DNA methylation status of PHD1, PHD2 and FIH has also been investigated in breast, cervical and prostate cancer cell lines, but the results are inconsistent $[12,14,15]$. These reports prompted us to study whether altered PHD1, PHD2, PHD3 and FIH expression levels may be correlated with the DNA methylation status of their promoter regions in primary cancerous and histopathologically unchanged colorectal tissue from the same ninety patients. We also evaluated the effect of 5-Aza-2'-deoxycytidine (5-dAzaC), an inhibitor of DNA methyltransferases (DNMTs), on the DNA methylation level of the PHD3 gene and its effect on PHD3 transcript and protein levels in HCT116 and DLD-1 CRC cells under hypoxic and normoxic conditions.

\section{Methods}

Antibodies and reagents

Rabbit polyclonal (Rp) anti-PHD1 (NB100-310), -PHD2 (NB100-137), -PHD3 (NB100-139) and -FIH (NB100-428) antibodies $(\mathrm{Ab})$ were provided by Novus Biologicals (Cambridge, UK). Rp anti-GAPDH Ab (FL-335) and goat anti-rabbit horseradish peroxidase (HRP)-conjugated $\mathrm{Ab}$ were provided by Santa Cruz Biotechnology (Santa Cruz, CA). 5-dAzaC was purchased from Sigma-Aldrich Co. (St. Louis, MO).

\section{Patient material}

Primary colonic adenocarcinoma tissues were collected between June 2009 and July 2012 from ninety patients who underwent radical surgical resection of the colon at the Department of General and Colorectal Surgery, Poznań University of Medical Sciences, Poland (Table 1). Histopathologically unchanged colonic mucosa located at least $10-20 \mathrm{~cm}$ away from the cancerous lesions was obtained from the same patients. Since ex vivo stress may influence protein stability, one set of samples was

Table 1 Demographic and histopathological classification including stage, grade and tumour type of patients with CRC

\begin{tabular}{|c|c|}
\hline Features & No. of patients \\
\hline Total no. of patients & 90 \\
\hline Gender (Female/Male) & $41 / 49$ \\
\hline $\begin{array}{c}\text { Mean }( \pm \text { SD) age at radical surgical resection } \\
\text { of colon (yrs) }\end{array}$ & $68.60 \pm 11.45$ \\
\hline \multicolumn{2}{|l|}{ CRC localization } \\
\hline Proximal colon (cecum to transverse) & 32 \\
\hline Distal colon (splenic flexure to sigmoid) & 18 \\
\hline Rectum & 40 \\
\hline \multicolumn{2}{|l|}{ Histological grade } \\
\hline G1 & 3 \\
\hline G2 & 65 \\
\hline G3 & 22 \\
\hline \multicolumn{2}{|l|}{ Dukes classification } \\
\hline A & 8 \\
\hline B & 35 \\
\hline C & 47 \\
\hline \multicolumn{2}{|l|}{ Tumour stage } \\
\hline $\mathrm{T} 1$ & 4 \\
\hline $\mathrm{T} 2$ & 10 \\
\hline $\mathrm{T} 3$ & 65 \\
\hline $\mathrm{T} 4$ & 11 \\
\hline
\end{tabular}


immediately snap-frozen in liquid nitrogen and stored at $-80^{\circ} \mathrm{C}$ until RNA/DNA/protein isolation [16]. Another set of samples was directed for histopathological examination. Histopathological classification including stage, grade and tumour type was performed by an experienced pathologist. No patients received preoperative chemo- or radiotherapy. Written informed consent was obtained from all participating individuals. The procedures of the study were approved by the Local Ethical Committee of Poznań University of Medical Sciences.

\section{Cell culture}

DLD-1 colon cancer cells were obtained from the American Type Culture Collection (Rockville, MD) and HCT116 cells were kindly provided by the Department of Experimental and Clinical Radiobiology, Maria Skłodowska-Curie Cancer Center, Institute of Oncology Branch, Gliwice, Poland. These cells were cultured in DMEM GibcoBRL (Grand Island, NY) containing 10\% heat-inactivated fetal bovine serum (FBS) and $2 \mathrm{mM}$ glutamine. To determine the effect of 5-dAzaC on DNA methylation, transcript and protein levels of selected genes, the HCT116 and DLD-1 cells were cultured for 24 hours in DMEM GibcoBRL (Grand Island, NY) supplemented with 10\% FBS from Sigma-Aldrich Co. (St. Louis, MO). Cells were then cultured under normoxic or hypoxic $\left(1 \% \mathrm{O}_{2}\right)$ conditions either in the absence or in the presence of $5-\mathrm{dAzaC}$ at a concentration of 1.00 or $5.00 \mu \mathrm{M}$ for 6,24 and 48 hours. Hypoxic conditions were achieved using a MCO-18 M multigas cell culture incubator, Sanyo (Wood Dale, IL), modified to permit flushing the chamber with a humidified mixture of $5 \% \mathrm{CO}_{2}, 94 \% \mathrm{~N}_{2}$. These cells were used for total DNA, RNA isolation, RQ-PCR, western blotting, and HRM analysis.

\section{Reverse transcription and real-time quantitative polymerase chain reaction (RQ-PCR) analysis}

Total RNA from primary tissues of patients with CRC and CRC cell lines was isolated according to the method of Chomczyński and Sacchi (1987) [17]. RNA samples were quantified and reverse-transcribed into cDNA. RQ-PCR was carried out in a Light Cycler ${ }^{\circ} 480$ Real-Time PCR System, Roche Diagnostics GmbH (Mannheim, Germany) using $\mathrm{SYBR}^{\oplus}$ Green I as detection dye. The target cDNA was quantified by the relative quantification method using a calibrator for primary tissue or respective controls for HCT116 and DLD-1 cells. The calibrator was prepared as a cDNA mix from all of the patients' samples and successive dilutions were used to create a standard curve as described in Relative Quantification Manual Roche Diagnostics GmbH, (Mannheim, Germany). For amplification, $1 \mu \mathrm{l}$ of total $(20 \mu \mathrm{l})$ cDNA solution was added to $9 \mu \mathrm{l}$ of $\mathrm{IQ}^{\mathrm{TM}} \mathrm{SYBR}^{\odot}$ Green Supermix, Bio-Rad Laboratories Inc. (Hercules, CA) with primers (Additional file 1). To prevent amplification of sequences from genomic DNA contamination, primers and/or amplicons were designed at exon/exon boundaries and covered all gene splice variants (Additional file 1). The quantity of PHD1, PHD2, PHD3 and FIH transcript in each sample was standardized by the geometric mean of two internal controls. The internal control genes were porphobilinogen deaminase (PBGD) and human mitochondrial ribosomal protein L19 (hMRPL19) (Additional file 1). They were selected from four candidate reference genes (PBGD, hMRPL, peptidylprolyl isomerase A- PPIA, hypoxanthine phosphoribosyltransferase 1- HPRT) based on the results achieved in geNorm VBA applet for Microsoft Excel (data not shown) $[18,19]$. The PHD1, PHD2, PHD3 and FIH transcript levels in the patients' tissues were expressed as multiplicity of cDNA concentrations in the calibrator. In HCT116 and DLD-1 cells, transcript levels were presented as multiplicity of the respective controls.

\section{Western blotting analysis}

Primary tissues from patients with CRC, HCT116 and DLD-1 cells were treated with lysis RIPA buffer and proteins were resuspended in sample buffer and separated on $10 \%$ Tris-glycine gel using sodium dodecyl sulfatepolyacrylamide gel electrophoresis (SDS-PAGE). Gel proteins were transferred to a nitrocellulose membrane, which was blocked with $5 \%$ milk in Tris/ $\mathrm{HCl}$ saline/Tween buffer. Immunodetection of bands was performed with Rp antiPHD1, -PHD2, -PHD3 and -FIH Ab, followed by incubation with goat anti-rabbit HRP-conjugated $\mathrm{Ab}$. To ensure equal protein loading of the lanes, the membrane was stripped and incubated with Rp anti-GAPDH Ab (FL-335), followed by incubation with goat anti-rabbit HRPconjugated Ab. Bands were revealed using SuperSignal West Femto Chemiluminescent Substrate, Thermo Fisher Scientific (Rockford, IL) and Biospectrum ${ }^{\oplus}$ Imaging System 500, UVP Ltd. (Upland, CA). The amounts of analyzed proteins were presented as the protein-to-GAPDH band optical density ratio. For HCT116 and DLD-1 cells cultured in the absence of 5-dAzaC, the ratio of PHD3 to GAPDH was assumed to be 1 .

\section{DNA isolation and bisulfite modification}

Genomic DNA was isolated using DNA Mammalian Genomic Purification Kit purchased from Sigma-Aldrich Co. (St. Louis, MO). $500 \mathrm{ng}$ of genomic DNA was subjected to bisulfite conversion of cytosine to uracil according to the EZ DNA Methylation $\mathrm{Kit}^{\mathrm{TM}}$ procedure from Zymo Research Corporation (Orange, CA). The position of $\mathrm{CpG}$ islands and binding sites of transcription factors located in the regulatory region of the promoter was determined by online programs [20-22]. 


\section{DNA methylation evaluation by bisulfite sequencing}

DNA fragments containing CpG dinucleotides located in the promoter region of the PHD1, PHD2, PHD3 and FIH genes were amplified from the bisulfite-modified DNA by the primer pairs (Additional file 1, Additional file 2) complementary to the bisulfite-DNA modified sequence. PCR amplification was performed by FastStart Taq DNA Polymerase from Roche Diagnostic GmbH (Mannheim, Germany). The PCR products were purified using Agarose Gel DNA Extraction Kit, Roche Diagnostic GmbH (Mannheim, Germany) with subsequent cloning into pGEM-T Easy Vector System I, Promega (Madison, WI) and transformation into TOPO10 E. coli strain cells. Plasmid DNA isolated from five positive bacterial clones was used for commercial sequencing of the cloned fragment of DNA. The results of bisulfite sequencing were assessed and presented using BiQ analyzer software and Bisulfite sequencing Data Presentation and Compilation (BDPC) web server, respectively [23,24].

\section{DNA methylation assessment by high resolution melting (HRM) analysis}

Methylation levels of DNA fragments located within the CpG island of the PHD1, PHD2, PHD3 and FIH genes (Additional file 2) were determined by Real Time PCR amplification of bisulfite treated DNA followed by HRM profile analysis by Light Cycler ${ }^{\circ} 480$ Real-Time PCR System, Roche Diagnostics GmbH (Mannheim, Germany). For PCR amplification, $1 \mu \mathrm{l}$ of the bisulfite treated DNA from patients, HCT116, DLD-1 cells, or standards, and primers (Additional file 1, Additional file 2) was added to $19 \mu \mathrm{l}$ of $5 \mathrm{X}$ Hot FIREPol EvaGreen HRM Mix, Solis BioDyne Co. (Tartu, Estonia). Standardized solutions of DNA methylation percentage were prepared by mixing methylated and non-methylated bisulfite treated DNA from Human Methylated/Non-methylated DNA Set, Zymo Research Corp. (Orange, CA) in different ratios. To determine the percentage of methylation, the HRM profiles of patient DNA PCR products were compared with HRM profiles of standard DNA PCR product $[25,26]$. HRM methylation analysis was performed using Light Cycler ${ }^{\circ} 80$ Gene Scanning software, Roche Diagnostics GmbH (Mannheim, Germany). Each PCR amplification and HRM profile analysis was performed in triplicate. Using HRM analysis we were able to detect heterogenous methylation with equal sensitivity (Additional file 3). The methylation for each patient was presented as a percentage of methylation in amplified fragments located in the $\mathrm{CpG}$ island of PHD1, PHD2, PHD3 and FIH. Since low levels of methylation may not demonstrate significant biological effect and we are not able to quantify all CpG dinucleotides within the analyzed $\mathrm{CpG}$ island, the percentage results were divided into three groups: $0-1 \%$ methylation, $1-10 \%$ methylation and 10-100\% methylation for statistical analysis [27-30].

\section{Statistical analysis}

The normality of the observed patient data distribution was assessed by Shapiro-Wilk test, and unpaired, twotailed $t$-test or U Mann-Whitney test was used to compare the mean values. The chi-square test was used to examine significance in DNA methylation. To evaluate the association between different ranges of DNA methylation (0-1\% methylation, $1-10 \%$ methylation and $10-100 \%$ methylation) and the ratio of cancerous tissue PHD3 mRNA level to histopathologically unchanged PHD3 mRNA level, the non-parametric Kruskal-Wallis test was employed. Data groups for cell lines were assessed by ANOVA to evaluate if there was significance $(\mathrm{P}<0.05)$ between the groups. For all experimental groups, which fulfilled the initial criterion, individual comparisons were performed by post hoc Tukey test with the assumption of two-tailed distribution. Statistically significant results were indicated by $\mathrm{p}<0.05$. Statistical analysis was performed with STATISTICA 6.0 software.

\section{Results}

PHD1, PHD2, PHD3 and FIH transcript and protein levels in primary cancerous and histopathologically unchanged tissues from patients with CRC

To compare PHD1, PHD2, PHD3, and FIH transcript and protein levels in cancerous and histopathologically unchanged tissues from ninety patients with CRC we used RQ-PCR and western blotting, respectively. We found significantly lower levels of PHD1, PHD2 and PHD3 transcript $(\mathrm{p}=0.00026 ; \mathrm{p}<0.00001 ; \mathrm{p}<0.00001)$ and protein $(\mathrm{p}=0.004164 ; \mathrm{p}=0.0071 ; \mathrm{p}<0.00001)$ in primary cancerous than in histopathologically unchanged tissues in ninety patients with CRC (Figure 1A, B; Figure 2). Moreover, we observed significantly lower levels of PHD1, PHD2, PHD3 transcript and protein in cancerous tissue in different age groups, among the genders, CRC localization, G2 and G3 histologic grade, levels of Dukes scale [31], and tumour stage (Additional file 4). There was no significant difference in the levels of FIH transcript between primary cancerous and histopathologically unchanged tissues in ninety patients with CRC $(\mathrm{p}=0.583)$ (Figure 1A). However, we observed a statistically higher level of FIH protein in primary cancerous than in histopathologically unchanged tissue $(\mathrm{p}=0.0169)$ (Figure 1B, Figure 2). We also found a significantly higher level of FIH protein in cancerous tissue in the male patient group $(\mathrm{p}=0.0210)$, and in patients aged above $60(\mathrm{p}=0.0257)$, with CRC localized in the rectum $(\mathrm{p}=0.031)$ and $\mathrm{G} 2$ histologic grade $(\mathrm{p}=$ 0.0226) (Additional file 4). 


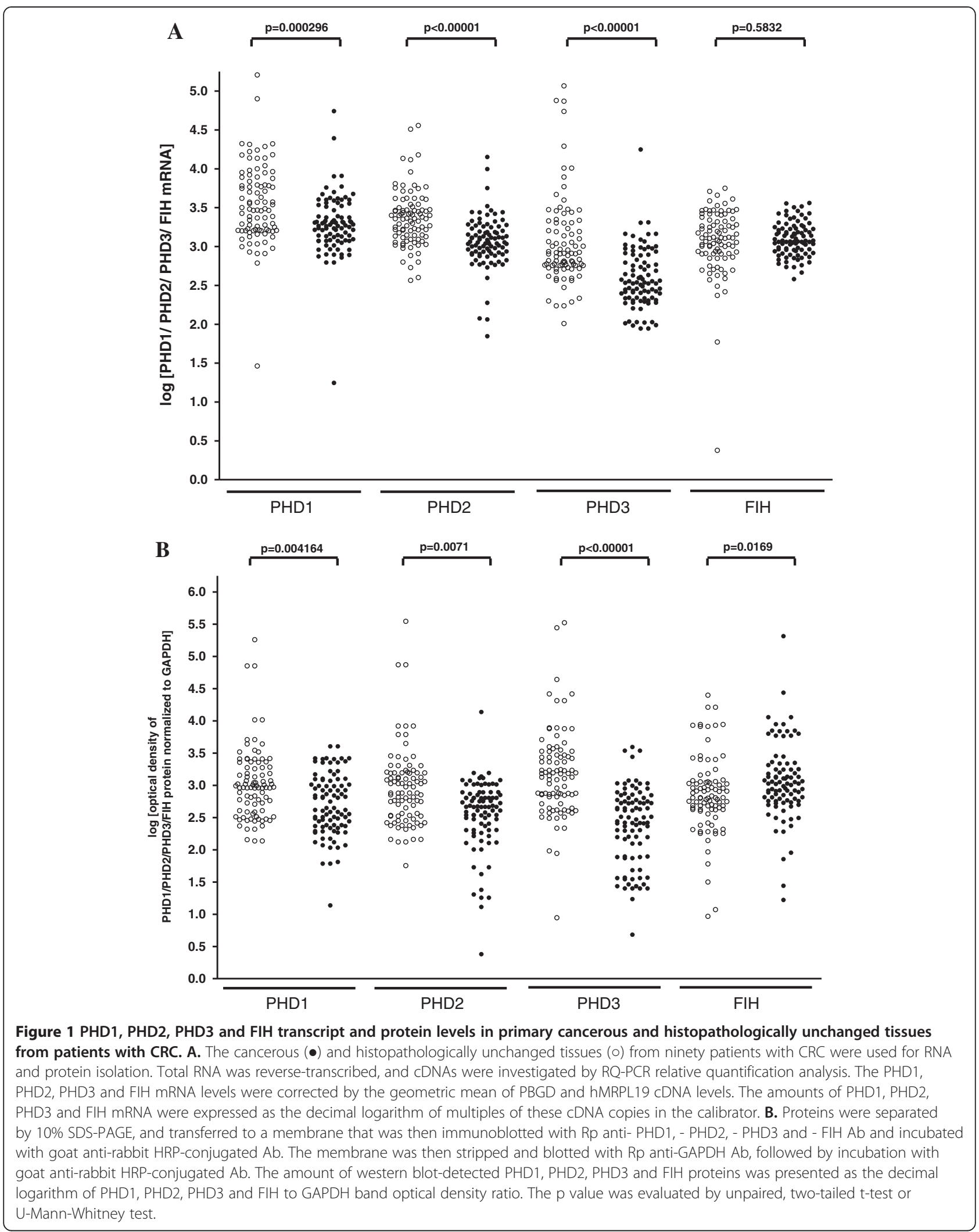




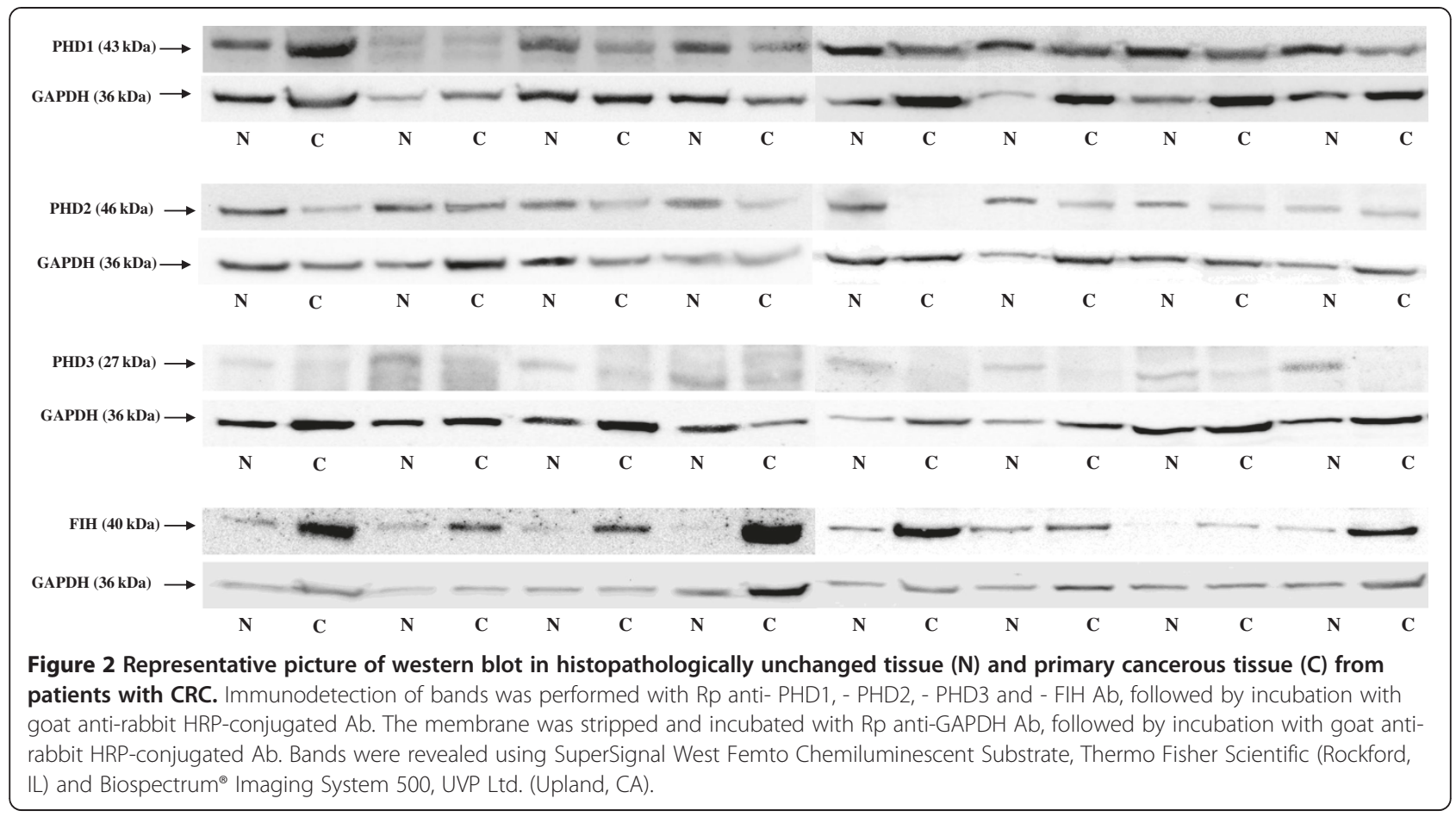

DNA methylation levels in primary cancerous and histopathologically unchanged tissues from patients with CRC

To compare DNA methylation levels in the promoter region of the PHD1, PHD2, PHD3, and FIH genes between DNA samples from cancerous and histopathologically unchanged tissues, we performed sodium bisulfite DNA sequencing and HRM analysis (Additional file 1, Additional file 2). Bisulfite sequencing was used for preliminary evaluation of DNA methylation in large regions of selected CpG islands in randomly selected patients. We detected a similar pattern of DNA methylation within all individual clones of each patient. The DNA methylation level evaluation for PHD3 revealed significant differences between cancerous and histopathologically unchanged tissue in region chr14: 34419 346-34 419943 (Figure 3B, Additional file 1, Additional file 2). However, we observed no changes of DNA methylation within the promoter of $P H D 3$ in region chr14: 34 419 929-34 420563 (Figure 3A, Additional file 1, Additional file 2). Moreover, we did not detect DNA methylation in the regulatory region of the PHD1, PHD2 and $F I H$ genes in cancerous and histopathologically unchanged tissue in selected patients with CRC (Additional file 1, Additional file 2, Additional file 5). To extend DNA methylation studies and to confirm bisulfite sequencing data for all analyzed genes, we employed HRM analysis of PCR amplified bisufite treated DNA for patients. Depending on the length of the $\mathrm{CpG}$ island and the amplification possibilities of bisulfite treated DNA, one to three primer pairs was used in HRM analysis (Additional file 1,
Additional file 2). In keeping with the bisulfite sequencing data, we observed no DNA methylation within the promoter region of the PHD1, PHD2 and FIH genes in cancerous and histopathologically unchanged tissue from ninety patients with CRC (Additional file 1, Additional file 2, Additional file 6). We also detected no DNA methylation for $P H D 3$ in region chr14: $34 \quad 419$ 922-34 420 080 in cancerous and histopathologically unchanged tissue using HRM analysis (Figure 3A, Additional file 1, Additional file 2). However, HRM evaluation showed a significant increase in the average DNA methylation level in cancerous compared to histopathologically unchanged tissue from ninety patients with $\mathrm{CRC}$ in the $\mathrm{CpG}$ island of the PHD3 gene in regions chr14: 34419 795-34 419935 and chr14: 34419 400-34 419538 (p < 0.00001) (Figure 3B; Table 2, Additional file 1, Additional file 2). HRM results were compared with those obtained in bisulfite sequencing for all analyzed genes in reconstituted samples. A similar pattern of DNA methylation was observed between these two methods (Figure 3). Moreover, we observed that an increase in the average DNA methylation level of PHD3 in regions chr14: 34 419 795-34 419 935 and chr14: 34 419 400-34 419538 correlated to a decrease in the ratio of cancerous-to-histopathologicallyunchanged tissue PHD3 mRNA level ( $<$ 0.0001) (Figure 4).

\section{DNA methylation level of the PHD1, PHD2 and FIH genes} in HCT116 and DLD-1 CRC cells

To assess DNA methylation levels in the promoter region of the PHD1, PHD2, and FIH genes in DLD-1 and 


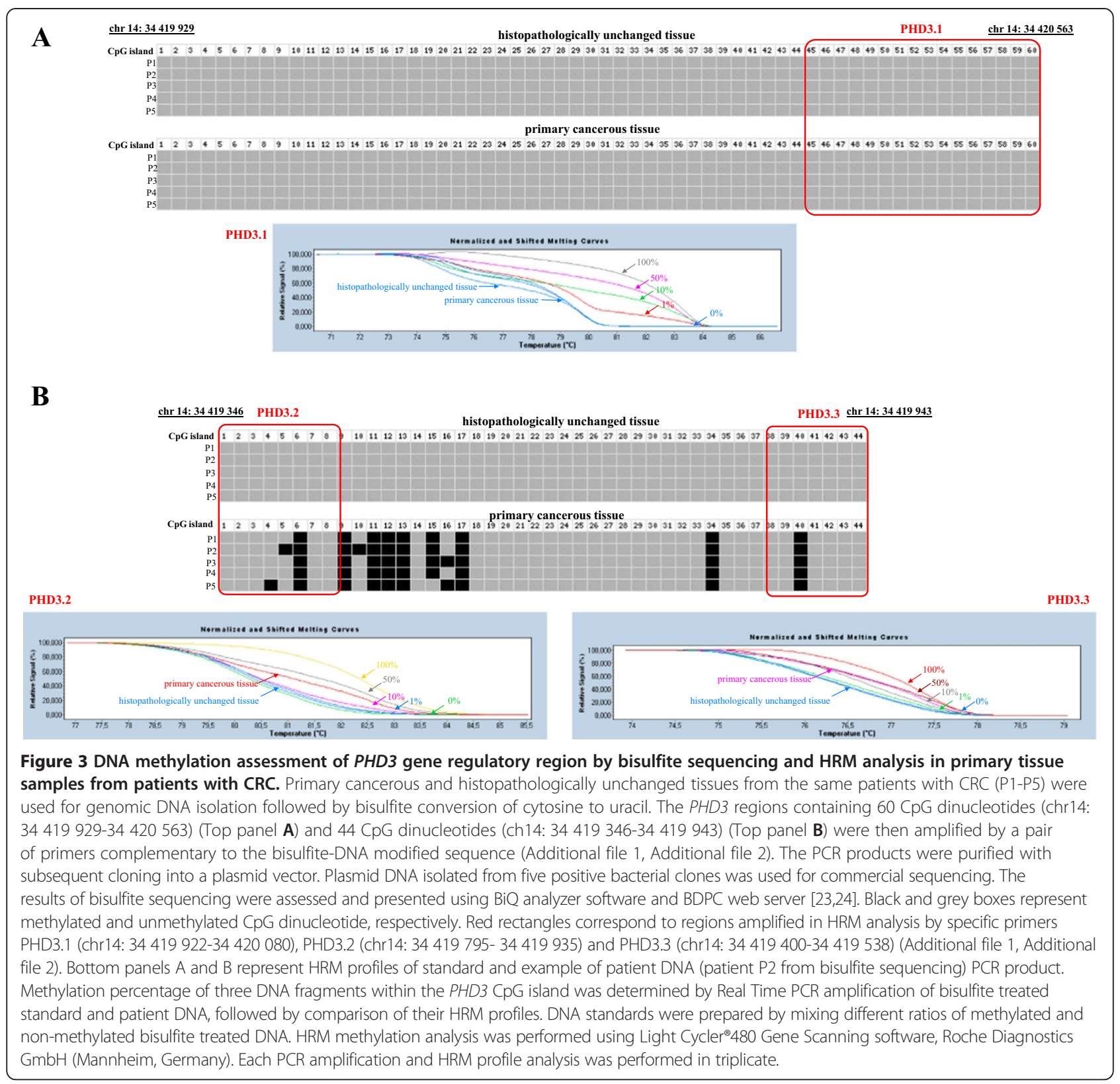

HCT116 cells, we performed HRM analysis (Additional file 1, Additional file 2). We observed no DNA methylation of the promoter region of PHD1, PHD2 and FIH gene in the analyzed regions using HRM analysis under hypoxic and normoxic conditions (Additional file 6).

\section{The hypermethylated PHD3 gene in HCT116 is not induced upon hypoxia conditions}

To evaluate the association between DNA methylation of the PHD3 gene and its expression in HCT116 and DLD-1 CRC cell lines we performed HRM analysis, RQ-PCR, and western blotting. We observed a high level of DNA methylation in HCT116 and no DNA methylation in
DLD-1 cells in the chr14: 34,419 922-34 420 080, chr14: 34 419 795-34 419935 and chr14: 34 419 400-34 419 538 regions of $P H D 3$ gene $\mathrm{CpG}$ island using HRM analysis in both hypoxic and normoxic conditions (Figure 5A). We detected a lower level of PHD3 transcript and protein in HCT116 cells compared to DLD-1 cells in both hypoxic and normoxic conditions (Figure 5B, C). However, statistical significance in these differences occurred only under hypoxic conditions (Figure 5B, C). Moreover, we observed a statistically significant induction of $P H D 3$ transcript and protein level upon hypoxia in DLD-1 cells, with no changes in HCT116 cells under the same conditions (Figure 5B, C). 
Table 2 Methylation level of the regulatory region of the PHD3 gene in primary cancerous tissue and histopathologically unchanged tissue sample from patients with CRC

\begin{tabular}{lccccc}
\hline & Total no. of patients & $<\mathbf{1 \%}$ methylation & $\mathbf{1 - 1 0 \%}$ methylation & $\mathbf{1 0 - 1 0 0 \% ~ m e t h y l a t i o n ~}$ & $\mathbf{p}^{\text {a }}$ \\
\hline $\begin{array}{c}\text { Histopathologically unchanged tissue } \\
\text { Primary cancerous tissue }\end{array}$ & 90 & 63 & 27 & 0 & 0 \\
\hline
\end{tabular}

The primary cancerous and histopathologically unchanged tissue samples from the same patients were used for genomic DNA isolation, followed by bisulfite conversion of cytosine to uracil. The DNA fragments of the CpG island were then amplified by three pairs of primers complementary to the bisulfite-DNA modified sequence (Additional file 1, Additional file 2). To determine the percentage of methylation, the HRM profiles of the patients' DNA PCR products were compared to HRM profiles of the prepared standard PCR products (Figure 3). DNA methylation of the PHD3 regulatory region for each patient was calculated as mean of the percentage of methylation in two DNA amplified fragments where the differences between primary cancerous and histopathologically unchanged tissue where observed. ${ }^{\text {a }}$ Chi square test.

5-dAzaC induced DNA demethylation of PHD3 promoter region, PHD3 transcript and protein contents in HCT116 cells, and did not affect PHD3 DNA methylation or expression levels in DLD-1 cells under hypoxic and normoxic conditions

In order to assess the effect of 5-dAzaC on DNA methylation and PHD3 gene expression levels we used HRM analysis, RQ-PCR, and western blotting. We observed no effect of 5-dAzaC treatment on the DNA methylation status in the analyzed regions of the PHD3 promoter region in DLD-1 cells upon hypoxic and normoxic conditions (Figure 6A, B, C). On the contrary, using HRM analysis we noticed significant DNA demethylation in chr14: 34 419 922-34 420 080, chr14: 34 419 795-34 419935 and chr14: 34419 400-34 419538 regions of the CpG island of the PHD3 gene in HCT116 cells cultured for 48 hrs in the presence of $5.00 \mu \mathrm{M} 5-\mathrm{dAzaC}$ in both hypoxic and normoxic conditions (Figure 6A, B, C). The changes in DNA methylation level were accompanied by 5 -dAzaC induced expression of PHD3 in HCT116 cells. We observed that 5 -dAzaC resulted in a progressive increase in PHD3 transcript levels in HCT116 cells and no significant changes for DLD-1 cells (Figure 7A). For HCT116 we found approximately a 2.45 - and 2.59-fold significant increase in PHD3 transcript levels at 48 hrs of incubation under normoxic and hypoxic conditions, respectively (Figure 7A). Alterations in PHD3 transcript levels in HCT116 cells were associated with increased PHD3 protein

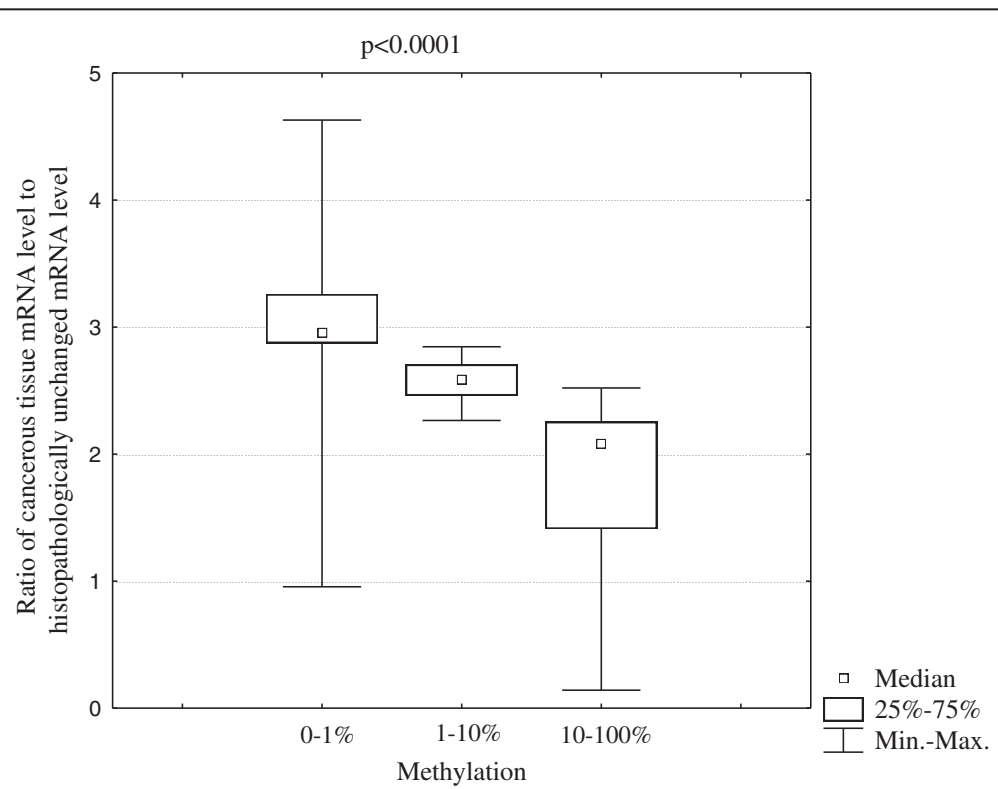

Figure 4 Ratio of cancerous PHD3 mRNA level to histopathologically unchanged tissue PHD3 mRNA level in three ranges of PHD3 methylation status: $\mathbf{0 - 1} \% ; \mathbf{1 - 1 0 \%}$ and $\mathbf{1 0}-\mathbf{1 0 0 \%}$. Methylation percentage of three DNA fragments within the PHD3 CpG island (Additional file 1, Additional file 2) was determined by Real Time PCR amplification of bisulfite treated standard and patient DNA, followed by comparison of their HRM profiles. The methylation for each patient was calculated as an average percentage of methylation in amplified fragments located in the CPG island of PHD3. The samples were divided into three groups for statistical analysis: 0-1\% methylation, 1-10\% methylation and 10-100\% methylation (Table 2) [28-30]. To evaluate the statistically significant difference in the ratio of cancerous PHD3 mRNA level to histopathologically unchanged tissue PHD3 mRNA level between the three DNA methylation ranges (0-1\% methylation, 1-10\% methylation and 10-100\% methylation), the non-parametric Kruskal-Wallis test was employed. 


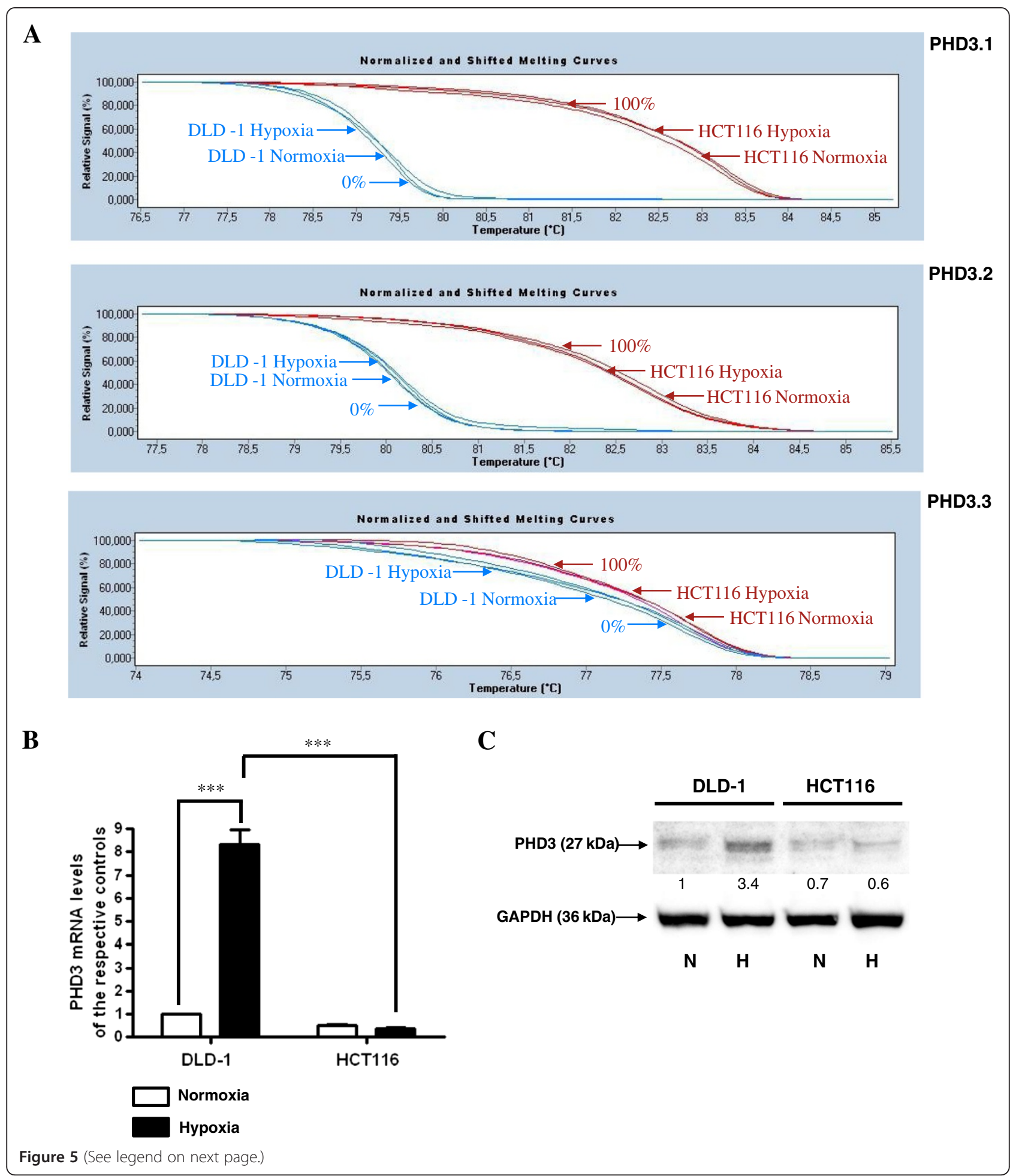


(See figure on previous page.)

Figure 5 DNA methylation and expression level of the PHD3 gene in HCT116 and DLD-1 CRC cells. A. HCT116 and DLD-1 cells were cultured under normoxic or hypoxic $\left(1 \% \mathrm{O}_{2}\right)$ conditions for 48 hrs. Cells were then used for DNA isolation followed by bisulfite modification. Methylation percentage of three DNA fragments within the PHD3 CpG island (Additional file 1, Additional file 2) in HCT116 and DLD-1 cells under hypoxic and normoxic conditions was determined by Real Time PCR amplification of bisulfite treated standard and cell line DNA, followed by comparison of their HRM profiles. B. Cells were cultured in DMEM either in hypoxic $\left(1 \% \mathrm{O}_{2}\right)$ or normoxic conditions for 48 hrs. After incubation, the cells were used for total RNA isolation and reverse transcription. The PHD3 CDNA levels were determined by RQ-PCR relative quantification analysis. RQ-PCR results were standardized by the geometric mean of PBGD and hMRPL19 CDNA levels. PHD3 CDNA levels are expressed as a multiplicity of these cDNA copies in the cell line's calibrator. C. Cells were cultured in DMEM either in hypoxic $\left(1 \% \mathrm{O}_{2}\right)(\mathbf{H})$ or normoxic (N) conditions for $48 \mathrm{hrs}$. Cells were then used for protein isolation. Proteins were separated by 10\% SDS-PAGE, and transferred to a membrane that was then immunoblotted with Rp anti - PHD3 Ab and incubated with goat anti-rabbit HRP-conjugated Ab. The membrane was then stripped and reblotted with Rp anti-GAPDH Ab, followed by incubation with goat anti-rabbit HRP-conjugated Ab. The band densitometry readings were normalized to GAPDH loading control. The ratio of PHD3 to GAPDH for DLD-1 in normoxic conditions was assumed to be 1.
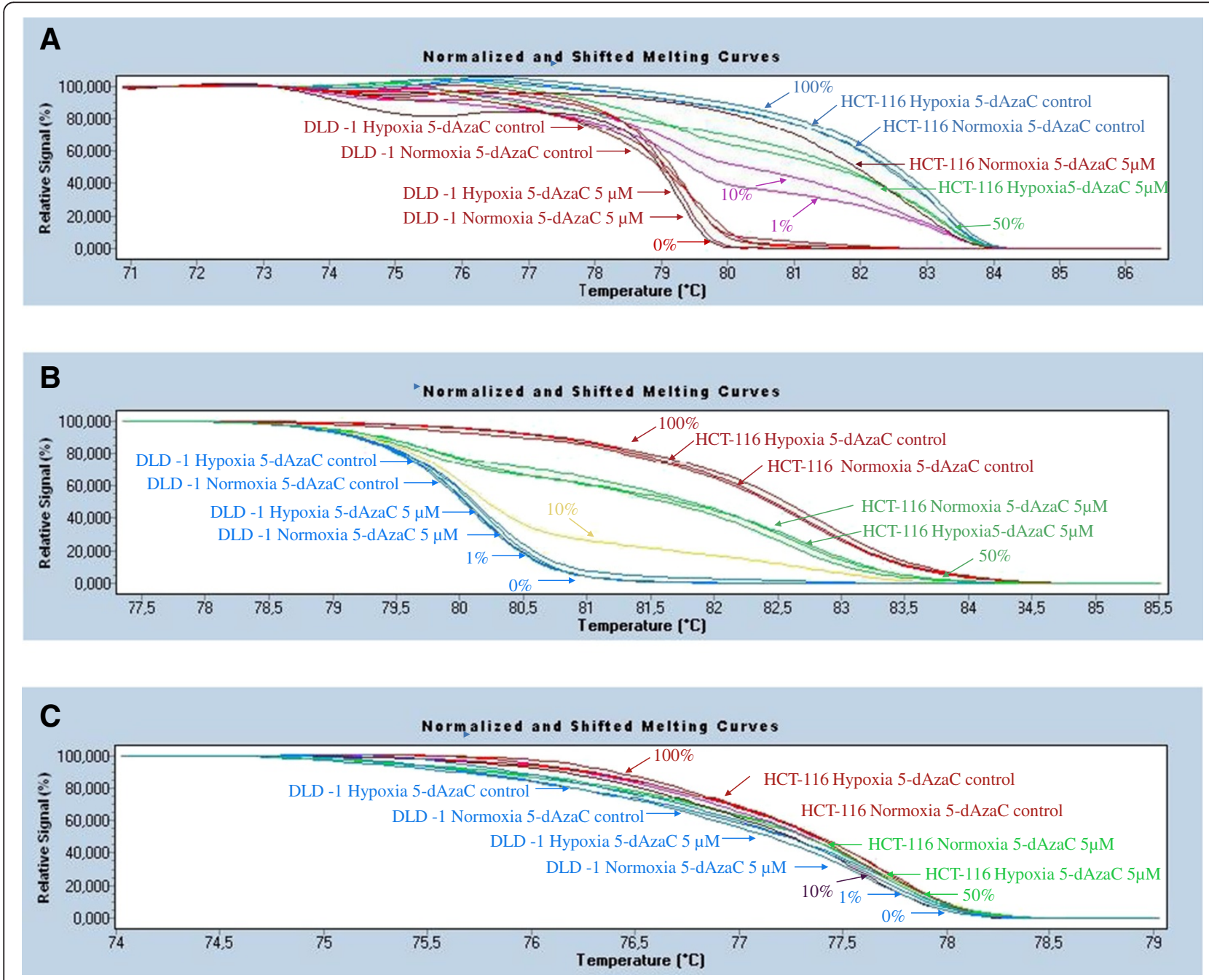

Figure 6 Effect of 5-dAzaC on PHD3 gene DNA methylation in HCT116 and DLD-1 CRC cells. HCT116 and DLD-1 cells were cultured under normoxic or hypoxic $\left(1 \% \mathrm{O}_{2}\right)$ conditions either in the absence or in the presence of 5-dAzaC at a concentration of $5.00 \mu \mathrm{M}$ for 48 hrs. Cells were then used for DNA isolation followed by bisulfite modification. Methylation percentage of three DNA fragments within the PHD3 CpG island: A (chr14: 34419 922-34 420 080), B (chr14: 34419 795-34 419 935) and C (chr14: 34419 400-34 419 538) (Additional file 1, Additional file 2) in HCT116 and DLD-1 cells under hypoxic and normoxic conditions was determined by Real Time PCR amplification of bisulfite treated standard and cell line DNA, followed by comparison of their HRM profiles. 


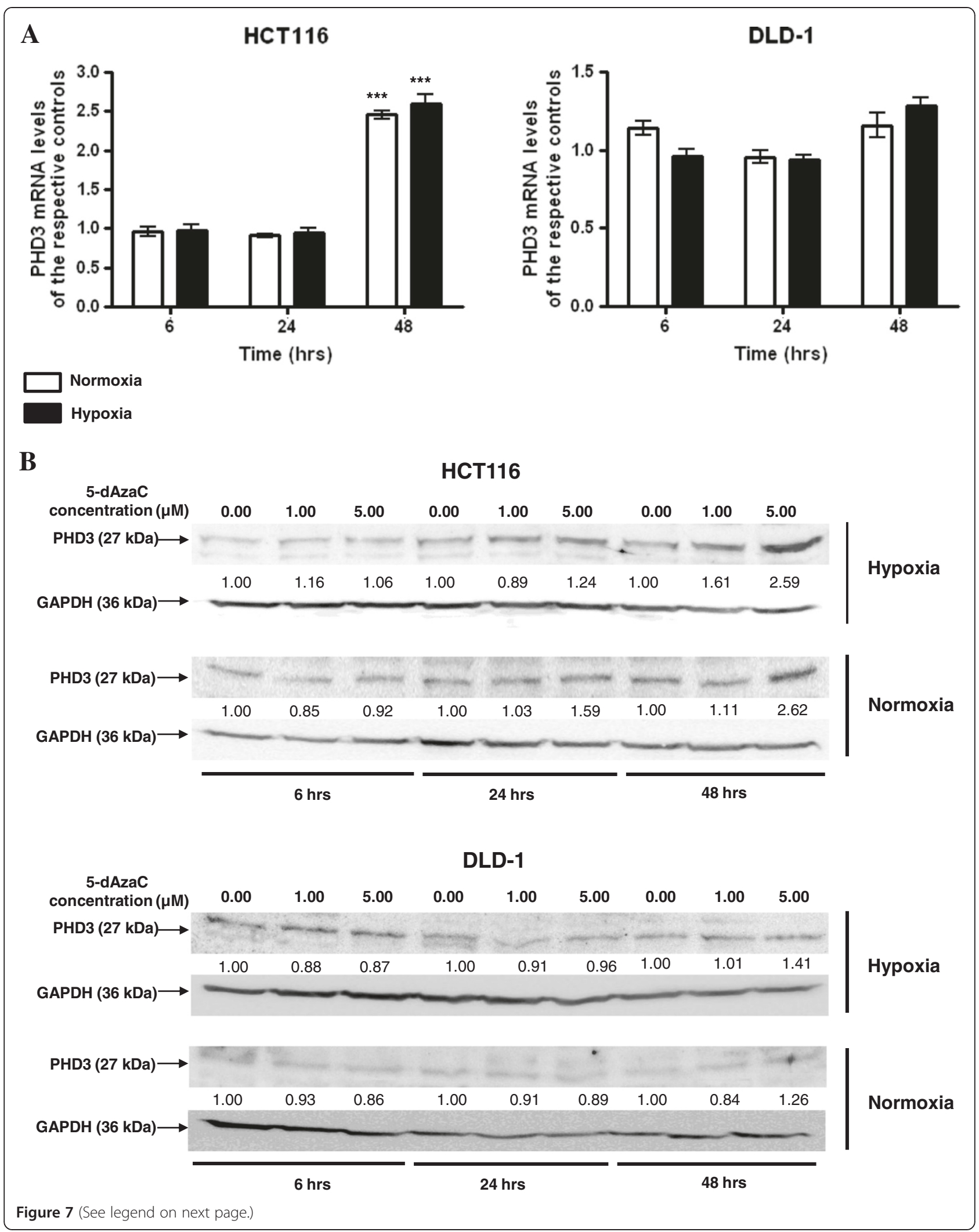


(See figure on previous page.)

Figure 7 5-dAzaC effect on PHD3 transcript (A) and protein (B) levels in HCT116 and DLD-1 CRC cells. HCT116 and DLD-1 cells were cultured in DMEM for 6, 24 and $48 \mathrm{~h}$ either in the absence or in the presence of 5-dAzaC at a concentration of 1.00 or $5.00 \mu \mathrm{M}$ under hypoxic or normoxic conditions. After incubation the cells were used for total RNA isolation and protein isolation. Total RNA was reverse-transcribed, and PHD3 CDNA levels were determined by RQ-PCR relative quantification analysis. RQ-PCR results were standardized by the geometric mean of PBGD and hMRPL19 CDNA levels. PHD3 CDNA levels are expressed as a multiplicity of the respective controls. Each sample was determined in triplicate and results are presented as the mean \pm SE from three experiments ${ }^{*} \mathrm{P}<0.05$. The cell protein was separated by $10 \% \mathrm{SDS}$-PAGE, and transferred to a membrane that was then immunoblotted with Rp anti - PHD3 Ab and incubated with goat anti-rabbit HRP-conjugated Ab. The membrane was then stripped and reblotted with Rp anti-GAPDH Ab, followed by incubation with goat anti-rabbit HRP-conjugated Ab. The band densitometry readings were normalized to GAPDH loading control. The ratio PHD3 to GAPDH for control was assumed to be 1.

levels in both hypoxic and normoxic conditions (Figure 7B). Densitometric analysis of western blotting bands indicated an approximately 2.59- and 2.62- fold increase in PHD3 protein level in HCT116 cells incubated with $5.00 \mu \mathrm{M}$ 5 -dAzaC for $48 \mathrm{hrs}$ as compared to the respective controls under hypoxic and normoxic conditions, respectively. Incubation of DLD-1 cells with 5-dAzaC at various concentrations for different time periods did not significantly increase PHD3 protein contents under either hypoxic or normoxic conditions (Figure 7B).

\section{Discussion}

The maintenance of oxygen homeostasis is a crucial physiological process [32]. Hypoxia is a common feature of human cancers, associated with higher aggressiveness and resistance to chemotherapy [33,34]. The cellular environment response to hypoxia is mediated by HIF, a heterodimeric transcriptional complex, which is posttranslationally regulated by prolyl and asparaginyl hydroxylases. The first group, PHD enzymes, govern the ubiquitin- mediated mechanism of HIF- $\alpha$ degradation under normoxic conditions [3]. Since hydroxylation reactions require the presence of oxygen, dioxygenases are unable to function in hypoxic conditions. Thus, the HIF is not directed to proteasomal degradation and may exert its effect on genes during CRC progression. However, oxygen concentration is not the only cause of altered PHD function during tumorigenesis. The contribution of PHD to cell behaviour depends on several conditions, including the relative abundance of PHD proteins in a specific tissue [3]. Since changes in the amount of available PHD enzymes will alter the rate of hydroxylation of HIF- $\alpha$, research has focused on the regulation of the quantity of PHDs. Aberrant expression of PHDs has been observed in a variety of human cancers. Detailed analysis of the expression patterns of all three PHD isoforms has shown differences depending on cancer cell type [7,35-37].

PHD1 protein levels were elevated in non-small cell type lung cancer (NSCLC) and pancreatic endocrine tumors [36,38]. Moreover, PHD1 inactivation resulted in lower levels of Cyclin D1 and impaired breast tumour formation [39]. However, it has been demonstrated that colon cancer cells expressing the PHD1 gene cause inhibition of tumour growth and angiogenesis under hypoxic conditions when injected into nude mice [40].

PHD2 was also previously studied in various cancer types. Low levels of PHD2 expression were correlated with poor survival rate in CRC and breast cancer $[9,41]$. Nonetheless, studies in head and neck squamous cell carcinoma (HNSCC) demonstrated an association between increased levels of nuclear PHD2 protein with strongly proliferative and malignant tumour phenotypes $[42,43]$. Furthermore, immunohistochemical studies have found that high PHD2 and PHD3 expression was significantly associated with worse 5-year survival rate in pancreaticobiliary cancer [44]. PHD3 transcript levels were shown to be increased in HNSCC, and in vitro analysis revealed inhibition of cell cycle progression in cancerous cells in the absence of PHD3 activity [45]. Elevated levels of PHD3 protein in cancerous tissue were also observed in immunohistochemical studies of NSCLC and gastric cancer $[38,46]$. However, PHD3 catalytic activity has demonstrated an ability to induce apoptosis independent of HIF in different cancer cell lines [12,47-49]. Additionally, Peurala et al. presented that increased PHD3 expression and was associated with an increased survival rate in breast cancer patients [41].

Discrepancies between PHD1, PHD2 and PHD3 experimental results might be partly explained by the demonstration that HIF and PHDs can form a feedback loop that limits hypoxic signaling in reoxygenated cells [50]. Moreover, these discrepancies imply a dual function of PHDs in the control of tumour progression that depends on cell type, other PHDs- interacting factors, and function independent of HIF. The HIF- independent functions of PHDs include PHD3 directed inhibition of phosphorylation of the inhibitor of $\kappa \beta$ kinase $\beta$ and activation of $\mathrm{NF} \kappa \beta$ in CRC, neuronal apoptosis and myoblast differentiation by PHD3, or control of myocardial development by PHD2 [8,51,52].

We found a statistically significant decrease in the expression levels of the PHD1, PHD2 and PHD3 genes in cancerous tissue compared to histopathologically unchanged colorectal tissue. Although we did not observe statistically significant differences in FIH transcript levels between cancerous and histopathologically unchanged 
colorectal tissue, we found a significant increase of $\mathrm{FIH}$ protein in CRC. FIH, in addition to PHDs, hydroxylates HIF- $\alpha$ at a conserved asparagine residue. Through this modification, FIH prevents interaction of HIF with its transcriptional coactivators [5]. More importantly, FIH is able to suppress HIF activity under severe hypoxic conditions, where PHDs are inactive [53,54]. Additionally, $\mathrm{FIH}$ exerts HIF-independent functions by interaction with pVHL, histone deacetylases, p105, Notch 1, and SOCS box proteins [55-58]. FIH is widely expressed; however, its expression varies between tissue and cancer types [7]. To date, FIH protein overexpression was correlated with a more malignant phenotype and poor prognosis in pancreatic endocrine tumours and NSCLC, respectively [36,38]. Moreover, it has been established that $F I H$ gene silencing reduced colon cancer cell proliferation in vitro and in vivo through the p53-p21 mediated pathway [54]. We observed a significant increase in the protein level of FIH in CRC tissue. This observation may result from E3 ligase activity of a member of seven in absentia homolog 1 (SIAH-1). Therefore, SIAH-1 facilitates ubiquitination and proteasomal degradation of FIH $[59,60]$. To date, SIAH-1 has been found to be widely distributed in human cell lines and tissues, including CRC, with a decreased expression in breast and hepatocellular cancer [61-63].

Since the prolyl and asparaginyl hydroxylases have so wide and profound an effect on tumorigenesis, studies on the regulation of the expression of these enzymes may help in our understanding of CRC progression. There are many factors involved in the development and occurrence of CRC, and they are classified as genetic, epigenetic and environmental [64-67]. One of the epigenetic mechanisms, namely altered DNA methylation in a gene's regulatory region, is observed from the early stages of lesions in aberrant crypt foci and hyperplastic polyps $[68,69]$. It has been shown that DNA hypermethylation of MLH1, MGMT, CDKN2A and many others is associated with CRC progression [67,70-72]. Our study is the first to investigate the methylation status of the promoter regulatory regions of $P H D 1, P H D 2, P H D 3$ and $F I H$ in primary cancerous tissue from patients with CRC, and HCT116, DLD-1 CRC cell lines. We did not observe DNA methylation within the CpG island of the PHD1, PHD2 and FIH gene promoter in either patients or cell lines. To date, the DNA methylation status of the promoter region of PHD1, PHD2, PHD3 and FIH was studied in a few cancers, including breast, prostate, cervical, melanoma, kidney and plasma cell neoplasia [12-15]. In cervical cancer cell lines the hypomethylation of the CpG island of the PHD2 gene promoter was associated with an increase in PHD2 expression [15]. Similarly to our results, no DNA methylation within the CpG island of PHD1, PHD2 and FIH has been observed in breast and plasma cell neoplasia [13,14]. There was also no DNA methylation in the promoter region of the PHD3 gene in clinical samples from breast and prostate cancer $[12,14]$. We also observed no DNA methylation within the PHD3 gene using bisulfite sequencing in region chr14: 34419 929-34 420563 and HRM analysis in region chr14: 34419 922-34 420080 in a group of patients, which is consistent with the results of Huang et al. and Place et al. [12,14]. However, we found a significantly higher level of DNA methylation within the first exon and intron of the PHD3 gene (chr14: 34419 346-34 419943 using bisulfite sequencing; chr14: 34 419 795-34 419935 and chr14: 34 419 400-34 419538 using HRM analysis) in cancerous tissue compared to histopathologically unchanged tissue. To the best of our knowledge, DNA methylation within the chr14: 34419 346-34 419 943, chr14: 34419 795-34 419935 and chr14: 34419 400-34 419538 regions was not previously analyzed in other studies. Data from Encyclopedia of DNA elements project showed that these regions are DNase I hypersensitive and able to bind various transcription factors, which suggests a promoter or enhancer activity [22]. Moreover, Pescador et al. (2005) identified a functional HRE within the first intron of the PHD3 gene and proposed a model of HIF-mediated hypoxic induction of PHD3 [73].

Since hypoxic conditions may induce global DNA hypomethylation in cancer cells, we investigated DNA methylation and expression levels of the PHD3 gene in HCT116 and DLD-1 cells under hypoxic and normoxic conditions [74]. We reported a high level of DNA methylation and no transcript and protein level changes under hypoxic and normoxic conditions in HCT116 cells. In the PHD3 gene promoter region in DLD-1 cells, we did not detect DNA methylation under either experimental condition, but we observed a significant induction of PHD3 transcript and protein level upon hypoxia. The PHD3 gene possesses in its promoter region a putative HRE and can be induced by HIF transcription factor complex under hypoxic conditions [35]. A lack of increase in PHD3 expression in HCT116 cells might be the result of DNA methylation of its promoter region in hypoxic conditions. To date, a decreased expression of PHD3 mRNA was correlated with high $\mathrm{CpG}$ island methylation status in plasma cell neoplasia and selected melanoma, prostate and mammary gland cancer cell lines [12,13].

In order to verify the role of DNA methylation within the CpG island of the PHD3 gene, we treated HCT116 and DLD-1 cells with 5-dAzaC under normoxic and hypoxic conditions. 5-dAzaC was previously shown to induce the expression of many genes in different types of cancer and inhibit the growth of CRC cells [75,76]. We observed significant DNA demethylation in the chr14: 34419 922-34 420 080, chr14: 34419 795-34 
419935 and chr14: $34 \quad 419$ 400-34 419538 regions of the CpG island of the PHD3 gene in HCT116 cells incubated with 5-dAzaC, which was correlated with an increase in PHD3 transcript and protein levels. The same regions were unmethylated in DLD-1 cells at different experimental conditions and 5-dAzaC did not affect PHD3 gene expression.

The presence of DNA hypermethylation of the PHD3 promoter region in a broad range of human cancers suggests its role in tumour survival. In glioblastoma cell lines, accumulation of PHD3 protected tumour cells against hypoxia-induced cell death via control of HIF [77]. However, reduction of PHD3 expression by DNA methylation may allow for stable HIF directed cellular response during hypoxia [12]. Moreover, in a subset of breast, prostate, melanoma and renal carcinoma cell lines, HIF- $1 \alpha$ accumulation during hypoxia was independent of DNA hypermethylation of the PHD3 promoter region, which suggests its role in other pathways and hydroxylase independent function [12].

\section{Conclusion}

Our results showed increased DNA methylation levels in the CpG island of PHD3 in CRC as compared to normal colonic epithelium from the same patients. These epigenetic alterations were associated with a significant decrease of PHD3 expression levels in patients with CRC. However, the reduction in PHD1 and PHD2 expression in cancerous tissue was not due to altered methylation within the CpG island in the promoter region of PHD1 and PHD2, respectively. Therefore, other mechanisms might be responsible for the observed decreased expression levels of PHD1 and PHD2 in CRC patients. Furthermore, we observed an increased level of FIH protein in CRC, with no changes in the FIH transcript level between cancerous and histopathologically unchanged colonic mucosa. Additionally, we observed different statistical values of transcript and protein levels of the analyzed genes for subgroups of patients classified according to different features. However, a larger group of patient and deeper molecular investigation of these observations should be studied to determine whether the results within subgroups may be clinically important.

We also found that an inhibitor of DNMTs, 5-dAzaC, induced DNA demethylation of the PHD3 promoter region, which was associated with increased transcript and protein levels in HCT116 cells under hypoxic and normoxic conditions.

Although we presented epigenetic transcriptional downregulation of $P H D 3$ gene expression in CRC patients and HCT116 CRC cell line for the first time, further studies are required to verify and determine the role of $\mathrm{CpG}$ island methylation in PHD3 expression in CRC to a greater extent. Moreover, DNA methylation is often associated with other alterations in chromatin structure, namely histone acetylation. High levels of DNA methylation accompanied with a low degree of histone acetylation may decrease the transcription of many genes [78]. In consideration of this, we also need to determine the possible role of histone modifications in PHD3 gene expression.

\section{Additional files}

\section{Additional file 1: Primer sequences. \\ Additional file 2: Schematic representation of the $\mathrm{CpG}$ distribution within the $5^{\prime}$ regulatory region of the PHD1 (A), PHD2 (B), PHD3 (C) and FIH (D) genes. \\ Additional file 3: Detection of heterogeneous methylation with HRM analysis. \\ Additional file 4: PHD1 (A), PHD2 (B), PHD3 (C), FIH (D) transcript and protein levels in primary cancerous and histopathologically unchanged tissue samples from patients with CRC. \\ Additional file 5: Bisulfite sequencing of DNA CpG rich region of the $P H D 1, P H D 2$ and $F I H$ genes in primary tissue samples from patients with CRC. \\ Additional file 6: DNA methylation assessment of the PHD1, PHD2 and FIH gene regulatory region by HRM analysis.}

\section{Competing interests}

The authors declare that they have no competing interests.

\section{Authors' contributions}

AAR contributed to designing the study, acquisition of data, analysis and interpretation of data, and in writing the manuscript. KEB and $\mathrm{KH}$ participated in the acquisition and interpretation of the data. As Principal Investigators, PK and JPP were involved in the intellectual and experimental programming of the study, the interpretation of data, and writing the manuscript. All authors read and approved the final manuscript.

\section{Acknowledgments}

Supported by grant No 502-01-01124182-07474 and 502-14-01124182-09624, Poznań University of Medical Sciences. The authors wish to acknowledge Dr Margarita Lianeri for her editorial assistance. We also thank Institute of Molecular Biology and Biotechnology, Adam Mickiewicz University for access to the MCO-18 M multigas cell culture incubator, Sanyo (Wood Dale, IL) supported by grant FNP FOCUS nr 3/2008.

\section{Author details}

'Department of Biochemistry and Molecular Biology, Poznań University of Medical Sciences, Poznan, Poland. ²Department of General and Colorectal Surgery, Poznań University of Medical Sciences, Poznan, Poland.

Received: 8 January 2013 Accepted: 21 October 2013

Published: 6 November 2013

\section{References}

1. Jemal A, Siegel R, Xu J, Ward E: Cancer statistics, 2010. CA Cancer J Clin 2010, 60(5):277-300.

2. Webb JD, Coleman ML, Pugh CW: Hypoxia, hypoxia-inducible factors (HIF), HIF hydroxylases and oxygen sensing. Cell Mol Life Sci 2009, 66(22):3539-3554.

3. Jokilehto T, Jaakkola PM: The role of HIF prolyl hydroxylases in tumour growth. J Cell Mol Med 2010, 14(4):758-770.

4. Brahimi-Horn MC, Bellot G, Pouyssegur J: Hypoxia and energetic tumour metabolism. Curr Opin Genet Dev 2011, 21(1):67-72.

5. Lando D, Peet DJ, Whelan DA, Gorman JJ, Whitelaw ML: Asparagine hydroxylation of the HIF transactivation domain a hypoxic switch. Science 2002, 295(5556):858-861. 
6. Lando D, Peet DJ, Gorman JJ, Whelan DA, Whitelaw ML, Bruick RK: $\mathrm{FIH}-1$ is an asparaginyl hydroxylase enzyme that regulates the transcriptional activity of hypoxia-inducible factor. Genes Dev 2002, 16(12):1466-1471.

7. Soilleux EJ, Turley H, Tian YM, Pugh CW, Gatter KC, Harris AL: Use of novel monoclonal antibodies to determine the expression and distribution of the hypoxia regulatory factors PHD-1, PHD-2, PHD-3 and FIH in normal and neoplastic human tissues. Histopathology 2005, 47(6):602-610.

8. Xue J, Li X, Jiao S, Wei Y, Wu G, Fang J: Prolyl hydroxylase-3 is down-regulated in colorectal cancer cells and inhibits IKKbeta independent of hydroxylase activity. Gastroenterology 2010, 138(2):606-615.

9. Xie G, Zheng L, Ou J, Huang H, He J, Li J, Pan F, Liang H: Low expression of prolyl hydroxylase 2 is associated with tumor grade and poor prognosis in patients with colorectal cancer. Exp Biol Med (Maywood) 2012, 237(7):860-866.

10. Jubb AM, Turley H, Moeller HC, Steers G, Han C, Li JL, Leek R, Tan EY, Singh B, Mortensen NJ, et al: Expression of delta-like ligand 4 (DII4) and markers of hypoxia in colon cancer. Br J Cancer 2009, 101(10):1749-1757.

11. Kondo Y: Epigenetic cross-talk between DNA methylation and histone modifications in human cancers. Yonsei Med J 2009, 50(4):455-463.

12. Place $T L$, Fitzgerald MP, Venkataraman S, Vorrink SU, Case AJ, Teoh ML, Domann FE: Aberrant promoter CpG methylation is a mechanism for impaired PHD3 expression in a diverse set of malignant cells. PLoS One 2011, 6(1):e14617.

13. Hatzimichael E, Dasoula A, Shah R, Syed N, Papoudou-Bai A, Coley HM, Dranitsaris G, Bourantas KL, Stebbing J, Crook T: The prolyl-hydroxylase EGLN3 and not EGLN1 is inactivated by methylation in plasma cell neoplasia. Eur J Haematol 2010, 84(1):47-51.

14. Huang KT, Mikeska T, Dobrovic A, Fox SB: DNA methylation analysis of the HIF-1alpha prolyl hydroxylase domain genes PHD1, PHD2, PHD3 and the factor inhibiting HIF gene FIH in invasive breast carcinomas. Histopathology 2010, 57(3):451-460.

15. Durczak M, Jagodzinski PP: Apicidin upregulates PHD2 prolyl hydroxylase gene expression in cervical cancer cells. Anticancer Drugs 2010, 21(6):619-624.

16. Espina V, Mueller C, Edmiston K, Sciro M, Petricoin EF, Liotta LA: Tissue is alive: new technologies are needed to address the problems of protein biomarker pre-analytical variability. Proteomics 2009, 3(8):874-882.

17. Chomczynski P, Sacchi N: Single-step method of RNA isolation by acid guanidinium thiocyanate-phenol-chloroform extraction. Anal Biochem 1987, 162(1):156-159.

18. Vandesompele J, De Preter K, Pattyn F, Poppe B, Van Roy N, De Paepe A, Speleman F: Accurate normalization of real-time quantitative RT-PCR data by geometric averaging of multiple internal control genes. Genome Biol 2002, 3(7):RESEARCH0034.

19. Sorby LA, Andersen SN, Bukholm IR, Jacobsen MB: Evaluation of suitable reference genes for normalization of real-time reverse transcription PCR analysis in colon cancer. J Exp Clin Cancer Res 2010, 29:144.

20. EMBOSS CpGPlot/CpGReport/Isochore: http://www.ebi.ac.uk/emboss/cpgplot/

21. CpG Island Searcher: http://cpgislands.usc.edu/

22. UCSC Genome Bioinformatics Site: http://genome.ucsc.edu/

23. Bock C, Reither S, Mikeska T, Paulsen M, Walter J, Lengauer T: BiQ Analyzer: visualization and quality control for DNA methylation data from bisulfite sequencing. Bioinformatics 2005, 21(21):4067-4068.

24. Rohde C, Zhang Y, Jurkowski TP, Stamerjohanns $H$, Reinhardt $R$, Jeltsch A: Bisulfite sequencing Data Presentation and Compilation (BDPC) web server-a useful tool for DNA methylation analysis. Nucleic Acids Res 2008, 36(5):e34

25. Wojdacz TK, Dobrovic A: Methylation-sensitive high resolution melting (MS-HRM): a new approach for sensitive and high-throughput assessment of methylation. Nucleic Acids Res 2007, 35(6):e41.

26. Rawluszko AA, Horbacka K, Krokowicz P, Jagodzinski PP: Decreased expression of 17-beta-hydroxysteroid dehydrogenase type 1 is associated with DNA hypermethylation in colorectal cancer located in the proximal colon. BMC Cancer 2011, 11(1):522

27. Hsieh CL: Dependence of transcriptional repression on CpG methylation density. Mol Cell Biol 1994, 14(8):5487-5494.

28. Shao Y, Zhang W, Zhang C, Wu Q, Yang H, Zhang J, Guan M, Wan J, Yu B: High-resolution melting analysis of BLU methylation levels in gastric, colorectal, and pancreatic cancers. Cancer Invest 2010, 28(6):642-648.
29. Dimitrakopoulos L, Vorkas PA, Georgoulias V, Lianidou ES: A closed-tube methylation-sensitive high resolution melting assay (MS-HRMA) for the semi-quantitative determination of CST6 promoter methylation in clinical samples. BMC Cancer 2012, 12:486.

30. Oster B, Thorsen K, Lamy P, Wojdacz TK, Hansen LL, Birkenkamp-Demtroder K, Sorensen KD, Laurberg S, Orntoft TF, Andersen CL: Identification and validation of highly frequent $\mathrm{CpG}$ island hypermethylation in colorectal adenomas and carcinomas. Int J Cancer 2011, 129(12):2855-2866.

31. Dukes CE, Bussey HJ: The spread of rectal cancer and its effect on prognosis. Br J Cancer 1958, 12(3):309-320.

32. Brahimi-Horn MC, Chiche J, Pouyssegur J: Hypoxia and cancer. J Mol Med 2007, 85(12):1301-1307.

33. Adams GE, Dische S, Fowler JF, Thomlinson RH: Hypoxic cell sensitisers in radiotherapy. Lancet 1976, 1(7952):186-188.

34. Comerford KM, Wallace TJ, Karhausen J, Louis NA, Montalto MC, Colgan SP: Hypoxia-inducible factor-1-dependent regulation of the multidrug resistance (MDR1) gene. Cancer Res 2002, 62(12):3387-3394.

35. Appelhoff RJ, Tian YM, Raval RR, Turley H, Harris AL, Pugh CW, Ratcliffe PJ, Gleadle JM: Differential function of the prolyl hydroxylases PHD1, PHD2, and PHD3 in the regulation of hypoxia-inducible factor. J Biol Chem 2004, 279(37):38458-38465.

36. Couvelard A, Deschamps L, Rebours V, Sauvanet A, Gatter K, Pezzella F, Ruszniewski P, Bedossa P: Overexpression of the oxygen sensors PHD-1, PHD-2, PHD-3, and FIH Is associated with tumor aggressiveness in pancreatic endocrine tumors. Clin Cancer Res 2008, 14(20):6634-6639.

37. Boddy JL, Fox SB, Han C, Campo L, Turley H, Kanga S, Malone PR, Harris AL: The androgen receptor is significantly associated with vascular endothelial growth factor and hypoxia sensing via hypoxia-inducible factors HIF-1a, HIF-2a, and the prolyl hydroxylases in human prostate cancer. Clin Cancer Res 2005, 11(21):7658-7663.

38. Andersen S, Donnem T, Stenvold H, Al-Saad S, Al-Shibli K, Busund LT, Bremnes RM: Overexpression of the HIF hydroxylases PHD1, PHD2, PHD3 and $\mathrm{FIH}$ are individually and collectively unfavorable prognosticators for NSCLC survival. PLoS One 2011, 6(8):e23847.

39. Zhang Q, Gu J, Li L, Liu J, Luo B, Cheung HW, Boehm JS, Ni M, Geisen C, Root DE, et al: Control of cyclin D1 and breast tumorigenesis by the EgIN2 prolyl hydroxylase. Cancer Cell 2009, 16(5):413-424.

40. Erez N, Milyavsky M, Eilam R, Shats I, Goldfinger N, Rotter V: Expression of prolyl-hydroxylase-1 (PHD1/EGLN2) suppresses hypoxia inducible factor-1alpha activation and inhibits tumor growth. Cancer Res 2003 63(24):8777-8783.

41. Peurala E, Koivunen $P$, Bloigu R, Haapasaari KM, Jukkola-Vuorinen A: Expressions of individual PHDs associate with good prognostic factors and increased proliferation in breast cancer patients. Breast Cancer Res Treat 2012, 133(1):179-188.

42. Jokilehto T, Rantanen K, Luukkaa M, Heikkinen P, Grenman R, Minn H, Kronqvist $\mathrm{P}$, Jaakkola $\mathrm{PM}$ : Overexpression and nuclear translocation of hypoxia-inducible factor prolyl hydroxylase PHD2 in head and neck squamous cell carcinoma is associated with tumor aggressiveness. Clin Cancer Res 2006, 12(4):1080-1087.

43. Jokilehto T, Hogel H, Heikkinen P, Rantanen K, Elenius K, Sundstrom J, Jaakkola PM: Retention of prolyl hydroxylase PHD2 in the cytoplasm prevents PHD2-induced anchorage-independent carcinoma cell growth. Exp Cell Res 2010, 316(7):1169-1178.

44. Gossage L, Zaitoun A, Fareed KR, Turley H, Aloysius M, Lobo DN, Harris AL, Madhusudan S: Expression of key hypoxia sensing prolyl-hydroxylases PHD1, -2 and -3 in pancreaticobiliary cancer. Histopathology 2010 56(7):908-920

45. Hogel H, Rantanen K, Jokilehto T, Grenman R, Jaakkola PM: Prolyl hydroxylase PHD3 enhances the hypoxic survival and G1 to $\mathrm{S}$ transition of carcinoma cells. PLoS One 2011, 6(11):e27112

46. Su C, Huang K, Sun L, Yang D, Zheng H, Gao C, Tong J, Zhang Q: Overexpression of the HIF hydroxylase PHD3 is a favorable prognosticator for gastric cancer. Med Oncol 2012.

47. Lee S, Nakamura E, Yang H, Wei W, Linggi MS, Sajan MP, Farese RV, Freeman RS, Carter BD, Kaelin WG Jr, et al: Neuronal apoptosis linked to EgIN3 prolyl hydroxylase and familial pheochromocytoma genes: developmental culling and cancer. Cancer Cell 2005, 8(2):155-167.

48. Schlisio S, Kenchappa RS, Vredeveld LC, George RE, Stewart R, Greulich H, Shahriari K, Nguyen NV, Pigny P, Dahia PL, et al: The kinesin KIF1Bbeta acts 
downstream from EgIN3 to induce apoptosis and is a potential 1p36 tumor suppressor. Genes Dev 2008, 22(7):884-893.

49. Rantanen K, Pursiheimo J, Hogel H, Himanen V, Metzen E, Jaakkola PM: Prolyl hydroxylase PHD3 activates oxygen-dependent protein aggregation. Mol Biol Cell 2008, 19(5):2231-2240.

50. D'Angelo G, Duplan E, Boyer N, Vigne P, Frelin C: Hypoxia up-regulates prolyl hydroxylase activity: a feedback mechanism that limits HIF-1 responses during reoxygenation. J Biol Chem 2003, 278(40):38183-38187.

51. Takeda K, Ho VC, Takeda H, Duan LJ, Nagy A, Fong GH: Placental but not heart defects are associated with elevated hypoxia-inducible factor alpha levels in mice lacking prolyl hydroxylase domain protein 2. Mol Cell Biol 2006, 26(22):8336-8346.

52. Fu J, Menzies K, Freeman RS, Taubman MB: EGLN3 prolyl hydroxylase regulates skeletal muscle differentiation and myogenin protein stability. J Biol Chem 2007, 282(17):12410-12418.

53. Dayan F, Roux D, Brahimi-Horn MC, Pouyssegur J, Mazure NM: The oxygen sensor factor-inhibiting hypoxia-inducible factor-1 controls expression of distinct genes through the bifunctional transcriptional character of hypoxia-inducible factor-1alpha. Cancer Res 2006, 66(7):3688-3698.

54. Pelletier J, Dayan F, Durivault J, Ilc K, Pecou E, Pouyssegur J, Mazure NM: The asparaginyl hydroxylase factor-inhibiting HIF is essential for tumor growth through suppression of the p53-p21 axis. Oncogene 2012, 31(24):2989-3001.

55. Mahon PC, Hirota K, Semenza GL: FIH-1: a novel protein that interacts with HIF-1alpha and VHL to mediate repression of HIF-1 transcriptional activity. Genes Dev 2001, 15(20):2675-2686.

56. Cockman ME, Lancaster DE, Stolze IP, Hewitson KS, McDonough MA, Coleman ML, Coles CH, Yu X, Hay RT, Ley SC, et al: Posttranslational hydroxylation of ankyrin repeats in IkappaB proteins by the hypoxiainducible factor (HIF) asparaginyl hydroxylase, factor inhibiting HIF (FIH). Proc Natl Acad Sci U S A 2006, 103(40):14767-14772.

57. Coleman ML, McDonough MA, Hewitson KS, Coles C, Mecinovic J, Edelmann M, Cook KM, Cockman ME, Lancaster DE, Kessler BM, et al: Asparaginyl hydroxylation of the Notch ankyrin repeat domain by factor inhibiting hypoxia-inducible factor. J Biol Chem 2007, 282(33):24027-24038.

58. Ferguson JE 3rd, Wu Y, Smith K, Charles P, Powers K, Wang H, Patterson C: ASB4 is a hydroxylation substrate of $\mathrm{FIH}$ and promotes vascular differentiation via an oxygen-dependent mechanism. Mol Cell Biol 2007, 27(18):6407-6419.

59. Fukuba $\mathrm{H}$, Takahashi T, Jin HG, Kohriyama T, Matsumoto M: Abundance of aspargynyl-hydroxylase FIH is regulated by Siah-1 under normoxic conditions. Neurosci Lett 2008, 433(3):209-214

60. Hu G, Fearon ER: Siah-1 N-terminal RING domain is required for proteolysis function, and $\mathrm{C}$-terminal sequences regulate oligomerization and binding to target proteins. Mol Cell Biol 1999, 19(1):724-732.

61. Bruzzoni-Giovanelli H, Fernandez P, Veiga L, Podgorniak M-P, Powell D, Candeias M, Mourah S, Calvo F, Marin M: Distinct expression patterns of the E3 ligase SIAH-1 and its partner Kid/KIF22 in normal tissues and in the breast tumoral processes. J Exp Clin Cancer Res 2010, 29(1):10.

62. Matsuo K, Satoh S, Okabe H, Nomura A, Maeda T, Yamaoka Y, Ikai I: SIAH1 inactivation correlates with tumor progression in hepatocellular carcinomas. Genes Chromosomes Cancer 2003, 36(3):283-291.

63. Wen YY, Yang ZQ, Song M, Li BL, Yao XH, Chen XL, Zhao J, Lu YY, Zhu JJ, Wang EH: The expression of SIAH1 is downregulated and associated with Bim and apoptosis in human breast cancer tissues and cells. Mol Carcinog 2010, 49(5):440-449.

64. Kim YI: Nutritional epigenetics: impact of folate deficiency on DNA methylation and colon cancer susceptibility. J Nutr 2005, 135(11):2703-2709.

65. Hermann S, Rohrmann S, Linseisen J: Lifestyle factors, obesity and the risk of colorectal adenomas in EPIC-Heidelberg. Cancer Causes Control 2009, 20(8):1397-1408

66. Fearon $E R$, Vogelstein B: A genetic model for colorectal tumorigenesis. Cell 1990, 61(5):759-767.

67. Kim MS, Lee J, Sidransky D: DNA methylation markers in colorectal cancer Cancer Metastasis Rev 2010, 29(1):181-206.

68. Chan AO, Broaddus RR, Houlihan PS, Issa JP, Hamilton SR, Rashid A: CpG island methylation in aberrant crypt foci of the colorectum. Am J Pathol 2002, 160(5):1823-1830.

69. Suehiro Y, Hinoda Y: Genetic and epigenetic changes in aberrant crypt foci and serrated polyps. Cancer Sci 2008, 99(6):1071-1076.
70. Kane MF, Loda M, Gaida GM, Lipman J, Mishra R, Goldman H, Jessup JM, Kolodner R: Methylation of the hMLH1 promoter correlates with lack of expression of hMLH1 in sporadic colon tumors and mismatch repairdefective human tumor cell lines. Cancer Res 1997, 57(5):808-811.

71. Veigl ML, Kasturi L, Olechnowicz J, Ma AH, Lutterbaugh JD, Periyasamy S, Li GM, Drummond J, Modrich PL, Sedwick WD, et al: Biallelic inactivation of hMLH1 by epigenetic gene silencing, a novel mechanism causing human MSI cancers. Proc Natl Acad Sci U S A 1998, 95(15):8698-8702

72. Herman JG, Merlo A, Mao L, Lapidus RG, Issa JP, Davidson NE, Sidransky D, Baylin SB: Inactivation of the CDKN2/p16/MTS1 gene is frequently associated with aberrant DNA methylation in all common human cancers. Cancer Res 1995, 55(20):4525-4530.

73. Pescador N, Cuevas Y, Naranjo S, Alcaide M, Villar D, Landazuri MO, Del Peso $L$ : Identification of a functional hypoxia-responsive element that regulates the expression of the egl nine homologue 3 (egln $3 / \mathrm{phd} 3$ ) gene. Biochem J 2005, 390(Pt 1):189-197.

74. Shahrzad S, Bertrand K, Minhas K, Coomber BL: Induction of DNA hypomethylation by tumor hypoxia. Epigenetics 2007, 2(2):119-125

75. Momparler RL: Pharmacology of 5-Aza-2'-deoxycytidine (decitabine). Semin Hematol 2005, 42(3 Suppl 2):S9-S16.

76. Ghoshal K, Motiwala T, Claus R, Yan P, Kutay H, Datta J, Majumder S, Bai S, Majumder A, Huang T, et al: HOXB13, a target of DNMT3B, is methylated at an upstream $\mathrm{CpG}$ island, and functions as a tumor suppressor in primary colorectal tumors. PLoS One 2010, 5(4):e10338.

77. Henze AT, Riedel J, Diem T, Wenner J, Flamme I, Pouyseggur J, Plate KH, Acker T: Prolyl hydroxylases 2 and 3 act in gliomas as protective negative feedback regulators of hypoxia-inducible factors. Cancer Res 2010, 70(1):357-366.

78. Luczak MW, Jagodzinski PP: The role of DNA methylation in cancer development. Folia Histochem Cytobiol 2006, 44(3):143-154.

\section{doi:10.1186/1471-2407-13-526}

Cite this article as: Rawluszko et al:: Expression and DNA methylation levels of prolyl hydroxylases PHD1, PHD2, PHD3 and asparaginyl hydroxylase FIH in colorectal cancer. BMC Cancer 2013 13:526.

\section{Submit your next manuscript to BioMed Central and take full advantage of:}

- Convenient online submission

- Thorough peer review

- No space constraints or color figure charges

- Immediate publication on acceptance

- Inclusion in PubMed, CAS, Scopus and Google Scholar

- Research which is freely available for redistribution 